\title{
Educação e Políticas Públicas: Uma análise do Programa Robótica na Escola à luz da teoria comportamental
}

\author{
Education na Public Policy: An analysis of the Robotics at School Program in the light of
}

behavioral theory

Educación y Políticas Públicas: Análisis del Programa de Robótica en la Escuela a la luz de la teoría del comportamiento

Recebido: 10/06/2021 | Revisado: 18/06/2021 | Aceito: 22/06/2021 | Publicado: 18/07/2021

\author{
Karla Vasconcelos Araújo \\ ORCID: https://orcid.org/0000-0001-6394-9094 \\ Universidade de Pernambuco, Brasil \\ E-mail: karla.araujo@upe.br \\ Luciana de Góes Silva \\ ORCID: https://orcid.org/0000-0002-7913-8066 \\ Universidade de Pernambuco, Brasil \\ E-mail: Luciana.goes@upe.br \\ José Luiz Alves \\ ORCID: https://orcid.org/0000-0003-2049-2084 \\ Universidade de Pernambuco, Brasil \\ E-mail: luiz.alves@upe.br \\ Pablo Aurélio Lacerda de Almeida Pinto \\ ORCID: https://orcid.org/0000-0001-5199-5181 \\ Universidade de Pernambuco, Brasil \\ E-mail: pablo.aurelio@upe.br
}

\begin{abstract}
Resumo
Com o objetivo de compreender o estímulo ao estudo da matemática e das disciplinas associadas às ciências da natureza, o presente estudo debruçou-se sobre as teorias do comportamento humano e nudges, para analisar o Programa Robótica na Escola, da Prefeitura do Recife. A metodologia adotada foi uma revisão bibliográfica, a análise documental do projeto disponibilizado pela Prefeitura e entrevistas não estruturadas realizada com professores do Centro de Educação, Tecnologia e Cidadania (CETEC) e Centro Comunitário da Paz (COMPAZ), que permitiu construir um arcabouço teórico sobre a temática e uma compreensão da amplitude do projeto, que abrange não apenas as escolas da rede municipal, como também as creches e núcleos do COMPAZ. Por mais que o Programa seja adaptado à realidade de cada espaço, é possível identificar que aspectos relacionados às teorias do comportamento humano e nudges, estão presentes na sua elaboração e implantação, a partir do momento que essa ação influencia no comportamento humano sem qualquer estímulo financeiro, visto que é oferecido em caráter público, sem tolher a liberdade, por ser uma disciplina eletiva, e oferece ao participante uma maior possibilidade de ter uma escolha nomeada como ideal, que é ser estudioso.
\end{abstract}

Palavras-chave: Nudges; Estímulos de comportamento; Robótica na escola; Políticas públicas; Educação.

\begin{abstract}
Aiming to understand the motivation to study the mathematics and the disciplines associated with the natural sciences, this study focused on the theories of human behavior and nudges, to analyses the Robotics at School Program, of Recife's City Hall. The methodology implemented was a bibliographic review, a documentary analysis of the project provided by the City Hall and a non-structured interview carried out with teachers from the Centro de Educação, Tecnologia e Cidadania (CETEC) and the Centro Comunitário da Paz (COMPAZ), which allowed the construction of a theoretical framework on the subject and an understanding of the wide scope of this project as it covers not only the municipal schools, but also the nursey schools and COMPAZ centers. As much as the Program is adapted to the reality of each space, it is possible to identify which aspects related to the theories of human behavior and nudges are present in its elaboration and implementation, from the moment when this action influences human behavior without any financial incentive. As it is offered on a public basis, without restricting freedom, as it is an optional subject, and offers the participant a greater possibility of having a choice nominated as ideal, which is to be a scholar. Keywords: Nudges; Behavioral stimuli; Robotics at school; Public policy; Education.
\end{abstract}




\section{Resumen}

Con el fin de comprender el estímulo al aprendizaje de matemática y disciplinas asociadas a las ciencias naturales, el presente trabajo utilizo teorías del comportamiento y de nudges para analizar el Programa Robótica na Escola, de la Alcadia de Recife. La metodología empleada fue una revisión bibliográfica, un análisis documental del proyecto de la Alcadía, y un diálogo con professores del Centro de Educação, Tecnologia e Cidadania (CETEC) y del Centro Comunitário da Paz (COMPAZ), lo que permitió construir el marco teórico sobre el tema y una mejor comprensión de la amplitud del proyecto, que alcanza no solo las escuelas municipales, como también las guarderías y los centros COMPAZ. Aunque el Programa sea adaptado a la realidad de cada espacio en donde se encuentra disponible, es posible identificar cuales aspectos relacionados a las teorías del comportamiento humano y de nudges están presentes en su elaboración e implementación, puesto que esta acción influencia el comportamiento humano sin cualquier incentivo financiero y como una disciplina electiva, oferecida sin costo, sin limitar la libertad individual, además de proporcionar al partícipe la posibilitad de elegir ser estudioso.

Palabras clave: Nudges; Estímulos conductuales; Robótica en la escuela; Política Pública; Educación.

\section{Introdução}

O binômio "ensino e aprendizagem" compreende uma interação entre dois processos comportamentais, ou seja, a relação entre comportamento de professores e comportamento dos alunos. Quando se observa a disciplina matemática, principalmente suas barreiras e dificuldades, fica implícito que seu processo compõe elementos como: prática, conceitos, abordagens e tendências e exigem um tratamento teórico que lhe sirva de base (Silva \& Martinez, 2017).

A continuidade do tradicionalismo no ensino da matemática, assim como de disciplinas que compõem as chamadas ciências da natureza, que têm como metodologia básica o livro e o quadro, fez com que a construção do conhecimento fosse, por vezes, ineficaz ou insuficiente. Reconhecer que a matemática é uma disciplina concreta, e que é através da natureza, das tecnologias e das construções humanas que ela se manifesta (Gervázio, 2017), serve de justificativa para que projetos educacionais sejam pensados e implementados pelos órgãos e secretarias de educação por todo o Brasil para que, inserida no mundo real, ela possa ser visualizada pelo aluno com maior sentido e aprendida com mais facilidade.

A preocupação que abrange o ensino da matemática se justifica pela sua importância na formação e inserção do indivíduo na sociedade, visto que a base da sociedade tecnológica está na disciplina (Svoksmose, 2001), sendo assim, a matéria vai além das salas de aula e se constitui como relevante para o desenvolvimento e a organização da sociedade.

Ao observar a importância da matemática não apenas como disciplina que se faz presente na base curricular da educação básica, mas como um meio fundamental de investigação e resolução de problemas, visto que privilegia o raciocínio, comunicação e argumentação (Pinto \& Pires, 2019), a visão sobre a disciplina se expande e se torna imprescindível o surgimento de novas metodologias que utilizem materiais concretos aproximando a teoria e a prática, pois essa abordagem minimizaria a dicotomia existente entre o saber escolar e o cotidiano.

Por parte das instituições públicas essa valorização da disciplina, de certo modo, já existe, mesmo que, ainda, não esteja amplamente adotada, algumas prefeituras, por meio de suas secretarias, desenvolvem novas perspectivas, a partir de propostas, programas e projetos, para sair de rankings ligados à evasão escolar, analfabetismo e da má qualidade da educação básica pública. É o que acontece com o Programa de Robótica na Escola, da Prefeitura do Recife, realizado por meio da Secretaria de Educação, que disponibiliza a robótica como disciplina eletiva, com o intuito de ampliar a qualidade do ensino (Recife, 2014).

Objetivando analisar o estímulo dado pelo Programa Robótica na Escola, da prefeitura do Recife, aos alunos no estudo da disciplina matemática e das ciências da natureza, o presente estudo debruçou-se nas construções associadas à teoria do comportamento humano, com foco em identificar pontos do Programa relacionados aos nudges, e propor possíveis direcionamentos que podem ser adotados e contextualizados à realidade da educação municipal com base nos estímulos de comportamento. Com isso, a metodologia adotada foi uma revisão bibliográfica, para construir uma base teórica sobre a temática em si, e a análise documental do projeto disponibilizado pela prefeitura, alinhados com entrevistas não estruturadas 
direcionadas aos gestores do Centro de Educação, Tecnologia e Cidadania (CETEC) e do Centro Comunitário da Paz (COMPAZ) para compreender como ocorre o estímulo à comunidade e aos estudantes para participarem do Programa.

\section{Revisão da Literatura}

A ciência econômica, em sua definição clássica, é a ciência social que estuda a tomada de decisão da aplicação de recursos escassos pela sociedade (Vasconcelos, et al., 2019). Embora o conceito tenha atravessado séculos mantendo coerência, o questionamento do papel do tomador de decisão, do seu nível de acesso à informação e capacidade de processamento e consequente aplicação em suas decisões econômicas passou por variadas abordagens.

Segundo a abordagem econômica clássica, baseada na teoria da racionalidade, o ser humano tem opções estáveis, constantes e transitivas (Ribeiro, et al., 2018). A tomada de decisão, nesta ótica, é feita pelo homo economicus, um ser eminentemente racional e que, ao tomar uma decisão, conhece todos os cursos de ação disponíveis, bem como as consequências da opção por qualquer um deles (Vasconcelos, et al., 2019). Partindo deste desenho, são esperados comportamentos sempre acertados e direcionados para os melhores resultados.

O estudo econômico viu surgir e tomar corpo, no decorrer do século XX, a abordagem comportamental da economia. Partindo de pressupostos fincados a partir de 1940 pela Teoria da Racionalidade Limitada (modelo Carnegie, exponenciado por Herbert Simon), a análise do comportamento econômico sobrelevou a importância da natureza humana do tomador de decisão, considerando todas as suas características e emoções aptas a funcionar como gatilhos e direcionadores de suas escolhas em caminhos não necessariamente alinhados como classicamente esperado pelos parâmetros racionais.

A linha de estudo, também conhecida como Behaviorismo (em referência a behavior, tradução do termo comportamento para a língua inglesa), tem em Richard Thaler seu principal expoente. A partir de meados da década de 70, o economista agregou à análise da tomada de decisão conhecimentos das áreas de psicologia, sociologia e as demais ciências que buscam entender em profundidade o comportamento, com o objetivo de ter deste uma percepção mais próxima da realidade.

Lastreado nos estudos de Daniel Kahneman e Amos Twersky (que teceram, na área da psicologia, importante estudo denominado Teoria da Perspectiva ou Teoria dos Prospectos), Thaler estruturou uma nova maneira de analisar a tomada de decisão, aderindo a uma visão descritivista - e não normativa - do comportamento do consumidor. A partir daí, sua diretriz foi criar um modelo econômico descritivo que retratasse acuradamente tal conduta (Thaler, 2019).

Kahneman (2012) desenvolveu o Modelo de Sistema Dual, em seu livro Rápido e Devagar - Duas formas de pensar, através do qual explica a existência de dois sistemas antagônicos e complementares dentro da mente humana, um agindo de maneira rápida e intuitiva (Sistema 1 ou Sistema Automático), resolvendo bem questões rápidas com aplicações de respostas que requerem baixo esforço cognitivo; e outro lento e detalhista, que analisa os problemas dados de maneira cuidadosa e precisa, requerendo, entretanto, maior tempo e esforço mental (Sistema 2 ou Sistema Reflexivo).

O ser humano é instado a tomar decisões mais variadas de maneira constante, em grande volume, sendo algumas delas capazes de apresentar importantes repercussões, devendo, por isso, ser analisadas com cautela e precisão. Na intenção de simplificar o processo e poder utilizar o Sistema 1, a mente humana, pela teoria, utiliza-se de heurísticas, que seriam atalhos desenvolvidos pelo nosso cérebro para tomar decisões de maneira rápida e de forma bastante razoável em uma grande variedade de assuntos. O uso desses caminhos, segundo Tocchetto et al. (2011) é o que ajuda a sobreviver às milhares de decisões que são tomadas diariamente sem que sejam, sequer, notadas. Os autores continuam a linha, explicando que a utilização de tais atalhos ocasiona erros sistemáticos, que são denominados de vieses.

A partir da percepção do tomador de decisões econômicas como alguém passível de sofrer influência de vieses - e na intenção de diminuir o seu impacto - é que surge a arquitetura das escolhas como meio de estimular o comportamento que leve ao melhor resultado - aquele que utiliza a maior gama possível de informações disponíveis, aumentando a probabilidade de 
alcançar o resultado ótimo. Os arquitetos de decisão, nos dizeres de Tabak \& Amaral (2018), "são aqueles que têm a responsabilidade de organizar o contexto no qual as pessoas tomam decisões".

Dentro desta perspectiva, Thaler desenvolve, ao lado de Carl Sunstein, a ideia de Nudge, consistente num estímulo de natureza não obrigatória que direciona o comportamento humano para o caminho com melhores resultados, do qual talvez ele se desviasse em decorrência dos vieses cognitivos. A arquitetura de escolhas se volta a melhorar a vida das pessoas concebendo ambientes favoráveis para o usuário: partindo da premissa de que as pessoas que escolhem são humanas, quem concebe as escolhas - o arquiteto de escolhas - deve facilitar sua vida o máximo possível (Thaler \& Sunstein, 2019). Daí a expressão Paternalismo Libertário, que leva à ideia da escolha do resultado ótimo a ser atingido, mas não obriga a conduta de maneira autoritária, preservando a esfera de autonomia do tomador de decisão.

Thaler e Sunstein (2019) trazem a ilustração de um treino de golfe em que as tacadas são dadas sem que seja possível visualizar o buraco onde a bola possivelmente cairia. Assim são as escolhas sobre as quais é apropriada a aplicação dos Nudges: opções e atitudes cujo benefício só será colhido a longo prazo ou é de difícil percepção imediata, fazendo com que o tomador de decisão nem sempre adote o caminho mais racional e que maximizaria os ganhos esperados.

Escolhas pertinentes a poupança para aposentadoria, cuidados com a saúde, adesão a cursos de qualificação e outras cujos resultados esperados não são imediatamente palpáveis requerem, no entender do arquiteto de escolhas, um "empurrãozinho" ou um estímulo adicional para que sejam realizadas, afastando a interferência de vieses cognitivos tendentes ao desvio dos resultados ótimos.

Se tal mecanismo pode ser aplicado dentro de uma unidade familiar, em que os pais antevêem o que consideram ser os melhores caminhos para seu filho e estimulam-no a segui-lo sem, entretanto, obrigá-lo - o Paternalismo Libertário igualmente pode ser aplicado dentro de uma corporação, por meio do estímulo à realização de cursos de reciclagem e qualificação para crescimento profissional, e, com igual propriedade, no âmbito da construção de políticas públicas; dentro da lógica de Estado de bem-estar social, em que os fins sociais são declinados e os indivíduos são estimulados a perfazer condutas orientadas a alcançá-los, sem ter sua esfera de liberdade anulada.

No sentido de diminuir a interferência das armadilhas cognitivas a que estão submetidos os agentes econômicos, o Estado ordena opções considerando os programas políticos previamente definidos.

Ribeiro \& Domingues (2018) abordam o conceito de nudge, contextualizando seu momento de destaque por ocasião da assunção de cargos estratégicos no governo norte-americano por parte de alguns pesquisadores da linha de estudo behaviorista, na gestão de Barack Obama, em paralelo ao lançamento da obra de Thaler e Sunstein, de mesmo nome (Thaler \& Sunstein, 2019). A partir de então, continua, o nudging, enquanto mecanismo sugestivo, e não obrigatório, é utilizado por diversos países em suas políticas públicas, no intento de implementar tais ferramentas no contexto de seus programas públicos.

Bradbury e Santori (2013), ao analisar o cenário do Reino Unido, consideram que a utilização da teoria dos nudges na área de educação constitui uma revisão da idéia neoliberal do tomador de decisão racional enquanto foco do elaborador de políticas públicas. Ademais, concluem que, além do redesenho do tomador de decisão e sua (ir)racionalidade, o novo paradigma provoca também uma remodelagem do elaborador de política pública (policy maker), $e$ dos seus próprios fins, vez que estes deixam de ser baseados em escolhas racionais e passam a focar em organizar e informar acerca das escolhas que os sujeitos irracionais fazem.

Cotejando o contexto brasileiro sob a égide da Constituição Federal de 1988, Souza et al. (2018) concluem pela aplicabilidade dos nugdes na confecção de políticas públicas, ponderando, entretanto, a necessária observância dos princípios da transparência e da liberdade, bem como dos valores constitucionais de publicidade, diversidade e igualdade, apontando como instrumental a participação popular, implementada, entre outras formas, por meio do orçamento participativo e demais 
meios deliberativos diretos da democracia contemporânea, desenvolvimento da governança colaborativa ou flexível, no cenário do que apontam como Estado Resiliente.

Da análise do papel do Estado como indutor de comportamentos, abrem-se ainda diversos debates éticos sobre a utilização de nudges, sendo levantadas críticas acerca da efetiva preservação da liberdade individual de escolha, quando são ofertadas opções previamente definidas pelo gestor público, resultando, segundo os críticos, numa redução do campo de liberdade das escolhas (Ribeiro, et al., 2018). Tocchetto et al (2011) questionam ainda como decidir em que direção influenciar as pessoas, asseverando a própria dificuldade em identificar seu conjunto de preferências, ao citar a dicotomia existente nos seres humanos, que são parcialmente planejadores e parcialmente executores.

\section{Metodologia}

A pesquisa apresenta uma abordagem qualitativa que difere da quantitativa por não utilizar, na análise do problema, um instrumento estatístico (Richardson, 2008). Com isso, sua preocupação não está em números e medições, o intuito é compreender os significados e características de determinada situação, “(...)ela trabalha com o universo dos significados, motivos, aspirações, crenças, valores, atitudes, o que corresponde a um espaço mais profundo das relações, dos processos e dos fenômenos que não podem ser reduzidos à operacionalização de variáveis” (Minayo, 1993, p.21-22).

Quanto aos procedimentos, o estudo se identifica com a pesquisa bibliográfica, que segundo Marconi e Lakatos (2020) é um tipo específico de produção científica feita com base em textos, sendo os artigos científicos o foco dos pesquisadores, e documental, onde os dados obtidos são provenientes de documentos para que sejam extraídas informações pertinentes e necessárias para a compreensão de um fenômeno (Flick, 2009). Ainda sobre o procedimento documental, é válido ressaltar que ele pode assumir duas finalidades: examinar materiais que ainda não sofreram nenhum tipo de análise anterior, ou podem ser reexaminados para novas interpretações ou informações complementares.

As fases relacionadas ao andamento do estudo consistiram em: i) pesquisa bibliográfica, com o intuito de compreender o desenvolvimento das teorias que compõem o comportamento humano; ii) a análise da Política Municipal de Tecnologia na Educação (PMTE) e do Programa Robótica na Escola; e iii) entrevistas não estruturadas com professores que participam do Programa no Centro de Educação, Tecnologia e Cidadania (CETEC) do Recife e com a gerente-geral do Centro Comunitário da Paz (COMPAZ) Governador Miguel Arraes.

\section{Resultados e Discussão}

O objeto do estudo foi o Programa Robótica na Escola, que surgiu no ano de 2014, após Geraldo Júlio, o então prefeito da cidade do Recife, assinar o Decreto No 27.699, que dispõe sobre a Política Municipal de Tecnologia na Educação (PMTE). Este regimento surge da necessidade em aplicar tecnologias para facilitar a aprendizagem dos educandos da rede municipal de ensino. Com isso, as unidades educacionais da cidade têm mais um dever, inserir em seus projetos políticopedagógicos o uso de tecnologias, pois assim estarão aptas a participar da PMTE. Os princípios norteadores do Programa estão pautados na liberdade de aprender, ensinar, pesquisar e divulgar cultura, o pensamento, a arte e o saber; na valorização do profissional da educação e garantia de formação adequada ao uso de todas as tecnologias robóticas introduzido na escola; na garantia do padrão de qualidade; na valorização da experiência extraescolar; na vinculação entre a educação escolar, o trabalho e as práticas sociais. Percebe-se que sua estruturação, assim como seus princípios, está associada à autonomia do discente que constrói e se projeta nos objetos de sua autoria, incumbido de propriedades culturais e únicas, sem desconsiderar as teorias tradicionais e fundamentais que regem o processo de construção dos aparatos tecnológicos. 
Os eixos estruturantes que compõem o Programa são a prova escrita da implantação de uma prática pedagógica emergente que não reconhece o modelo tradicional de ensino como o único capaz de mediar o processo de ensino e aprendizagem. O primeiro eixo estruturante é o 'Estudo e pesquisa que fundamentam o uso da robótica na escola' e trata dos encontros realizados com professores, professores multiplicadores, técnicos, profissionais do Núcleo de Pesquisa, Avaliação e Currículo em Tecnologia na Educação e outros engajados no programa ou que têm interesse em pesquisar, relatar experiências, compartilhar saberes e construir conhecimentos. O segundo eixo temático compreende a 'Robótica na escola e seus aspectos curriculares' e agrega a interdisciplinaridade (Japiassu, 1976; Freire, 1987) - a partir da comunicação entre as diversas áreas do conhecimento - e a transversalidade - com uma disciplina não obrigatória que tem uma abordagem refletindo a cultura de transformação e os conhecimentos prévios dos estudantes. Por último, tem-se o eixo da 'Robótica e projetos' que estimula o caráter ativo dos envolvidos - com estímulos para a participação dos pais e comunidade, e do incentivo para que estudantes sejam capazes de planejar as atividades e definirem ações e trajetórias.

Além de promover o uso pedagógico das tecnologias, também foram instituídos outros objetivos, como o de fomentar a melhoria do processo de ensino e aprendizagem, de promover a formação dos agentes educacionais, de contribuir com a inclusão digital e com a preparação dos jovens para o mercado de trabalho a partir do acesso e uso de tecnologias e inovação. Esse formato de prática pedagógica, utilizando recursos tecnológicos, é um facilitador para que do paradigma educacional emergente, que tem como um de seus princípios construção conjunta da teoria com a prática, a partir do momento que a construção do conhecimento não se fundamenta única e exclusivamente na memorização das informações, mas na sua compreensão e assimilação com a realidade (Araújo \& Belian, 2018).

Para que as atividades sejam desenvolvidas, o Programa prevê que os conteúdos sejam tratados considerando três linhas de ação: Robótica com Ferramentas - com a utilização de resíduos de produtos eletroeletrônicos e atividades que envolvem a criação, projeção e planejamento de artefatos eletroeletrônicos fixos ou autônomos -, Robótica de Encaixe destinada aos estudantes das creches, para estimular a criança a perceber e diferenciar cores, formas, empilhar, montar, desmontar, classificar e ordenar, auto-organizar - e Robótica Humanoide - adaptada ao contexto de cada escola a partir do interesse dos professores em levar mais um meio de viabilizar a aprendizagem aos seus alunos, sendo porém importante que os professores sejam coerentes com o conhecimento de seus alunos e com o nível de aprendizagem que julgarem adequados, pois, para essa linha de ação, não existe uma idade pré-determinada.

Com os artefatos desenvolvidos no Projeto, os estudantes concorrem em torneios locais, regionais e mesmo internacionais, já tendo obtido diversas premiações, tais como o Tricampeonato na Olimpíada Brasileira de Robótica (OBR) em 2019, que assegurou-lhes vaga para disputar o mundial em Portugal, em 2020, na competição Robocup Junior (Recife, 2019). Ainda no ano de 2019, estudantes da rede municipal de ensino do Recife conquistaram a vaga na Olimpíada Mundial de Robótica, na categoria Júnior, programado para ocorrer na cidade de Győr, na Hungria. Nos anos de 2016 e em 2017, conseguiram alcançar o oitavo lugar na Robocup - Campeonato Mundial de Robótica, que aconteceu na Alemanha e no Japão, respectivamente (Algomais, 2019).

Gary Becker e Schultz, na construção da Teoria do Capital Humano, tratam da decisão de investir em educação, treinamento, assistência médica, aperfeiçoamento ao conhecimento já existente, levando em conta os custos e benefícios dessa decisão (Moretto, 1997). Tal escolha ficaria a cargo do indivíduo; Thaler (2019), então, menciona que poucos alunos de ensino médio e superior perfazem uma análise cuidadosa deste investimento, preferindo estudar a disciplina que mais gosta. Tal raciocínio de ponderação, de escolha, é essencial para compreensão do cenário escopo da presente análise sob a ótica da economia comportamental.

Considerando o formato atualmente empregado para acesso ao ensino da robótica na rede municipal de ensino da cidade do Recife, que abrange estudantes desde a educação infantil até os anos finais do ensino fundamental, e também as 
crianças das creches, e no intuito de utilizar o interesse demonstrado pelas crianças como estímulo em sua tomada de decisão, algumas arquiteturas poderiam ser colocadas no intuito de funcionar como estímulo de ordem não obrigatória no caso em análise.

Damgaard \& Nielsen (2018) empreenderam estudo detalhado sobre a aplicação de nudges na área educacional, analisando numerosas intervenções realizadas. Experimentos utilizando o conhecimento sobre os variados vieses, usualmente estudados em adultos, foram aplicados em crianças de diferentes condições socioeconômicas e variada faixa etária, tocando pontos como aversão à perda, tendência à escolha padrão (default), acesso à informação de retorno (feedback), influência do viés do presente (e a consequente dificuldade do autocontrole diante do trade-off do custo imediato para benefício futuro), sempre analisando os estímulos e escolhas no contexto de sua educação. Seu estudo pontua inicialmente as limitações de atenção e cognição inerentes à tenra idade como importante barreira para boas decisões em escolhas complexas, tais como as relativas à educação. E assevera, ao fim, que poucas intervenções produzem bons efeitos para todos; acentuando que, enquanto alguns tipos de intervenção demonstram melhores resultados para estudantes de situação socioeconômica mais favorecida, não repetem tal desempenho quando aplicadas aos de situação menos favorecida e vice-versa.

Por meio das entrevistas não estruturadas com os professores do CETEC e com a gestora do COMPAZ, foi possível observar também pontos de melhoria, considerando os estudos da teoria comportamental e aplicação dos nudges. Uma possibilidade seria que as crianças fossem automaticamente matriculadas em turmas ou atividades extras de robótica, como torneios interescolares ou grupos de pesquisa e desenvolvimento de protótipos ligados a entes da iniciativa privada ou a outros centros de estudo na área da robótica, sendo sua manutenção no grupo condicionada a uma taxa de frequência escolar superior a 90\%, além de aproveitamento superior a $80 \%$ em todas as disciplinas. Tratar-se-ia da aplicação da dinâmica de escolha obrigatória ou adesão automática (dinâmica conhecida como opt-out), em que o estudante teria, inicialmente, oportunidade de ter contato com mais uma atividade na área de robótica, podendo engajar-se e se sentir estimulado a continuar. Sua retirada voluntária (opt-out) seria possível a qualquer tempo, desde que manifestasse vontade, ou caso não atingisse os critérios colocados.

Seria também, de certa forma, a aplicação da lógica do viés do status quo, colocada por Thaler e Sunstein (2019), ao tratar do programa Poupe mais Amanhã, em que funcionários de uma empresa eram automaticamente incluídos num plano de aposentadoria, sem que precisassem manifestar sua vontade de maneira clara. Sua saída voluntária era permitida a qualquer momento, o que, segundo os dados levantados pelos autores, não ocasionou uma taxa de retirada maior que 0,6 ponto percentual maior do que antes da implantação de adesão automática. Tocchetto e Porto Júnior (2011), tratando deste viés, falam da falta de preocupação das pessoas em abandonar a regra padrão. Pode-se pensar também no aspecto de seguir o rebanho, outro viés tratado na sequência pelos mesmos autores, também chamado de comportamento de manada.

Outra importante questão de estímulo é a existência do feedback, considerada por Thaler \& Sunstein (2019) como a melhor forma de ajudar a melhorar o desempenho dos humanos. Como dito acima, um dos motivos de os seres humanos terem frequentemente seu comportamento afetado pelos vieses deriva do fato de o resultado de suas condutas não ser imediatamente palpável (relembrar o exemplo das jogadas de golfe sem possibilidade de ver o buraco). É neste tipo de escolha, geralmente de longo prazo, que os nudges são mais úteis. Escolhas que requerem investimentos presentes para colheita de ganhos futuros, tais como dedicar-se com afinco às atividades escolares e ter um bom aproveitamento nos estudos, embora racionalmente tenham supremacia clara e inquestionável sobre as demais opções, na prática, nem sempre conseguem ser executadas.

Neste sentido, o feedback em seus diferentes formatos (a foto em miniatura das câmeras digitais; o lembrete do notebook de que a bateria vai acabar e o cabo precisa ser reconectado) é um nudge útil para melhorar o desempenho do ser humano. Da mesma forma, a transparência os progressos alcançados pelos alunos tanto dentro da atividade de robótica quanto 
nas disciplinas às quais se dedicaram para ter bons resultados, bem como o alerta, em tempo real, de intervenções e reforços a serem implementados são boas ferramentas de estímulo de comportamento.

Especificamente no que toca ao fornecimento de informação, Bergman (2020), embora assevere que a comunicação entre escola e pais tende a aumentar o engajamento destes e melhorar os resultados dos estudantes, ressalva que meramente franquear-lhe acesso online às informações escolares de seus filhos não necessariamente melhora seus resultados, posto que, apesar de disponíveis, os dados muitas vezes não são acessados. Pontua, entretanto, que intervenções simples, como o fornecimento de informações da conta (login) podem melhorar a performance parental e salienta os baixos custos apresentados pelas intervenções voltadas ao maior acesso da família a tais informações.

Ao reconhecer a importância e necessidade de desenvolver uma nova abordagem no ensino, é necessário também refletir sobre como estimular o público-alvo, de modo que ele não apenas compreenda a importância dessa adaptação, mas que também queira ingressar no projeto, exercendo seu papel discente de maneira engajada e participativa.

\section{Considerações Finais}

Como visto, a economia comportamental analisa o agente ativo das decisões econômicas como ser humano, dotado, portanto, de emoções e inconsistências de comportamento também humanas. Se o escopo for direcionado a crianças e adolescentes, o resultado, se não for o mesmo, será alguns pontos mais distante do esperado pela economia adepto da escola clássica (utilização plena das informações disponíveis, com óbvia escolha da melhor opção apresentada, que levará à maximização de ganhos, ou resultado ótimo). Considerando que tomar decisões é parte da vida, a aplicação de nudges no contexto da educação pode ajudar crianças a perceber as escolhas como parte de suas vidas e desenvolver sua habilidade para discernir cada escolha para benefícios de curto e longo prazos (PARK \& CLEMSON, 2020).

O presente estudo, a partir de uma pesquisa bibliográfica, foi capaz de obter um arcabouço teórico consistente, no que tange aos estímulos de comportamento e nudges, identificando, inclusive, experimentos anteriores que já desenvolviam o tema contextualizado à educação. A partir de conversas informais com profissionais que atuam no CETEC e COMPAZ, foi possível observar uma ligação entre o Programa de Robótica, oferecido pela Prefeitura do Recife, e aspectos associados aos estímulos de comportamento e nudges.

O desenvolvimento das atividades nos grupos de robótica envolve, de maneira transversal, conhecimentos de disciplinas da grade curricular, e isso faz com que os alunos se sintam estimulados a desenvolver as competências necessárias à participação nas Olimpíadas de Robótica e até outros eventos relacionados. Neste contexto, a demonstração de que o sucesso do projeto está intimamente ligada ao ganho de conhecimento nas disciplinas regulares, enquanto mecanismo devolutivo de informação acerca do desempenho do aluno (feedback) pode servir como um estímulo à sua maior dedicação nas disciplinasbase, com vistas a obter maior sucesso nos torneios de robótica.

Outro aspecto do projeto de robótica, para estimular comportamentos esperados ou ideais dos estudantes consiste no fato de que, se no estudo, por excelência, fala-se de uma escolha que requer custos atuais para ganhos futuros, atraindo a interferência do viés do presente, a sensação de sucesso e ganhos imediatos decorrentes do próprio esforço gerados pela participação nas competições de robótica trazem os resultados positivos para mais próximo do momento presente do tomador de decisão, minorando o efeito do referido viés. Assim, embora o foco específico não recaia num futuro profissional perfeitamente delineado, a dedicação requerida aos estudos para amealhar os bons resultados nos projetos e torneios acabam por requerer do aluno dedicação que trazem impacto positivo em seus resultados letivos.

A contribuição da pesquisa está na observância de um projeto pensado e disponibilizado de forma gratuita e eletiva aos alunos da rede municipal de ensino, que funciona como estimulante para os estudos da matemática e de disciplinas associadas às ciências da natureza. Porém, os autores reconhecem que a análise partiu de um único ponto em todo esse 
processo, ou seja, foram analisadas apenas as informações documentais e as percepções dos professores envolvidos no Programa; os alunos não participaram da construção do estudo, com isso não foi possível compreender o estímulo por parte dos alunos. Sendo assim, a sugestão, para futuras pesquisas, está justamente em, i) como esses alunos percebem esse estímulo? ii) de que forma participam de todo o processo? iii) é possível perceber em números as mudanças no desempenho escolar (notas ou conceitos alcançados) antes e depois de seu envolvimento nos grupos de robótica? iv) os resultados estão sendo satisfatórios? v) de que maneira as comunidades, que também compõem o grupo participante, enxergam as mudanças ocasionadas pela implantação do Programa? vi) concluída a etapa da educação básica, que repercussões a participação nos projetos de robótica pode ter nas etapas subsequentes da vida escolar e profissional dos estudantes? vii) haveria um impacto do projeto e dos interesses por ele despertados na escolha da área profissional a ser seguida? viii) há repercussão na decisão dos estudantes continuarem ou não sua trajetória escolar para além da educação básica, evoluindo para formação técnica ou de nível superior?

Percebe-se que há várias questões possivelmente colocadas, algumas das quais demandando coleta de dados de longo prazo, mas cujas respostas seriam de grande valia para o entendimento acadêmico da aplicabilidade dos conceitos econômicocomportamentais na esfera da educação, apresentando, assim, grande importância instrumental para o gestor elaborador de políticas públicas da área respectiva. A elaboração de estudos futuros cotejando os pontos acima declinados tem, desta forma, bom potencial de desenvolvimento e as contribuições eventualmente alcançadas apresentam relevância e densidade tanto científica quanto pragmática.

\section{Referências}

Algomais. (2019). Alunos da rede municipal do Recife disputam Olimpíada Mundial de Robótica. <http://revista.algomais.com/educacao/alunos-da-redemunicipal-do-recife-disputam-olimpiada-mundial-de-robotica>

Araújo, R., \& Belian, R. (2018). Concepções de professores universitários sobre inovação pedagógica. Revista Internacional de Educação Superior, 4(2), 387400 .

Ariely, D. (2020). Previsivelmente irracional - As forças invisíveis que nos levam a tomar decisões erradas. Sextante.

Bergman, P. (2020). Nudging technology use: Descriptive and experimental evidence from school information systems. Education Finance and Policy, 15(4), 623-647.

Bradbury, A., Mcgimpsey, I., \& Santori, D. (2013). Revising rationality: The use of 'Nudge' approaches in neoliberal education policy. Journal of Education Policy, 28(2), 247-267.

Damgaard, M. T., \& Nielsen, H. S. (2018). Nudging in education. Economics of Education Review, 64, 313-342.

Decreto n.27699, de 17 de janeiro de 2014. Dispõe sobre a Política Municipal de Tecnologia na Educação - PMTE, executada no âmbito da Secretaria de Educação, promoverá o uso pedagógico das tecnologias na Rede Municipal de Ensino do Recife, em todos os níveis de ensino. Recife, PE.

Flick, U. (2009). Introdução à pesquisa qualitativa. Artmed.

França, M.C.S. (2015). A racionalidade limitada à luz da análise econômica do direito. Universidade de Brasília, Brasil.

Freire, P. (1987). Pedagogia do oprimido. Paz e Terra.

Gervázio, S.N. (2017). Materiais concretos e manipulativos: uma alternativa para simplificar o processo de ensino/aprendizagem da matemática e incentivar a pesquisa. Revista Eletrônica Paulista de Matemática, 9, 42-55.

Japiassu, H. (1976). Interdisciplinaridade e patologia do saber. Imago.

Kahneman, D. (2012). Rápido e devagar: duas formas de pensar. Objetiva.

Lazear, E.P. (2000). Economic imperialism. The Quarterly Journal of Economics, 115(1), 99-146.

Marconi, M.A., \& Lakatos, E.M. (2020). Fundamentos de metodologia científica. Atlas.

Minayo, M.C.S. (1993). Pesquisa social: teoria, métodos e criatividade. Vozes.

Moretto, C. (1997). O capital humano e a ciência econômica: algumas considerações. Revista Teoria e Evidência Econômica, 5(9), 67-80.

Motta, F.C.P., \& Vasconcelos, I.F.G. (2018). Teoria geral da administração. Cengage. 
Research, Society and Development, v. 10, n. 8, e11810817058, 2021 (CC BY 4.0) | ISSN 2525-3409 | DOI: http://dx.doi.org/10.33448/rsd-v10i8.17058

Park, M., \& Clemson, C. (2020).Using nudge theory in early childhood classrooms. Childhood Education, 96(6), $22-31$.

Pinto, D.M.R., \& Pires, M.A.L.M. (2019). O ensino da matemática e sua função na formação do indivíduo e de sua cidadania na educação. Rematec: Revista de Matemática, Ensino e Cultura, 14(32), 118-130.

Portal da Educação. (2019). Estudantes da rede do Recife são tricampeões na Olimpíada Brasileira de Robótica. <http://www.portaldaeducacao.recife.pe.gov.br/groups/estudantes-da-rede-do-recife-s-o-tricampe-es-na-olimp-ada-brasileira-de-rob-tica>

Possa, A.A.C., Santos, B.C., Padre, D., Leal, E., Freitas, E.A., Agatti, F.A.S., Silva, G.F.O., Alencar, H., \& Alves, M.R. (2020). Iniciativas comportamentais para redução da evasão escolar dos jovens de 15 a 29 anos em tempos de pandemia. Boletim Economia Empírica, 1(4), 125-134.

Prefeitura Municipal do Recife. (2014). Programa robótica na escola [Projeto]. Recife: Secretaria de educação.

Ramiro, T., \& Fernandez, R.G. (2017). O nudge na prática: algumas aplicações do paternalismo do paternalismo libertário às políticas públicas. Textos de Economia, 20(1), 01-18.

Ribeiro, M.C.P., \& Domingues, V.H. (2018). Economia comportamental e direito: a racionalidade em mudança. Revista Brasileira de Políticas Públicas, 8(2), 456-471.

Richardson, R.J. (2008). Pesquisa social-métodos e técnicas. Atlas.

Silva, M.V.D.C. (2016). Introdução às teorias econômicas. UFBA.

Silva, R.Q., \& Martinez, M.L.S. (2017). Dificuldades na matemática básica: o processo de ensino-aprendizagem para a vida. In: IV Seminário Internacional de Representações Sociais, Subjetividade e Educação, 1-12.

Skovsmose, O. (2001). Educação matemática crítica: a questão da democracia. Papirus.

Souza, L.C., Ramos, K.T.F., Perdigão, S.C.R.V. (2018). Análise crítica da orientação de cidadãos como método para otimizar decisões públicas por meio da técnica nudge. Revista Brasileira de Políticas Públicas, 8(2), 234-250.

Tabak, B.M., \& Amaral, P.H.R. (2018). Vieses cognitivos e desenho de políticas públicas. Revista Brasileira de Políticas Públicas, 8(2), 472-491.

Thaler, R.H., \& Sunstein, C.R. (2019). Nudge: como tomar melhores decisões sobre saúde, dinheiro e felicidade. Objetiva.

Tocchetto, D.G., \& Júnior,S.S.P. (2011). Arghhhhh!!! Eu nunca mais vou comer pimenta... Oba! Pimenta! Homer Simpson, arquitetura de escolha e políticas públicas. Revista Economia \& Tecnologia, 7(1), 101-115. 